\title{
The Growth-factor Requirements of Haemophilus influenzae
}

\author{
By L. B. HOLT \\ The Wright-Fleming Institute, St Mary's Hospital Medical School, \\ London, W. 2
}

(Received 7 July 1961)

\section{SUMMARY}

Fifteen strains of Haemophilus influenzae were found to require for growth, in addition to coenzyme 1 (diphosphopyridine nucleotide; DPN) and haematin, the following substances: pantothenic acid, thiamine, uracil. Some of the strains also required a purine, accepting xanthine, hypoxanthine or guanine, but not adenine. Cysteine (or glutathione) was also needed for luxuriant growth. A medium is described which yields crops of about $10^{10}$ organisms $/ \mathrm{ml}$. after incubation for $18 \mathrm{hr}$. at $34^{\circ}$. Sheep red cells, but not horse red cells, contain a DPN-ase, located in the stroma, which rapidly destroys any DPN added to them and also destroys the contained DPN when the cells are lysed.

\section{INTRODUCTION}

Davis $(1917,1921 a, b)$ showed that two quite different growth factors are required for the growth of Haemophilus influenzae. These were later identified as haematin (Fildes, 1921; Lwoff \& Lwoff, 1937 $a, b, c$; Lwoff \& Pirosky, 1937) and cozymase (Lwoff \& Lwoff, 1937 $a, b$ ). Although it was confirmed that the addition of cozymase (diphosphopyridine nucleotide; DPN) and haematin (10 $\mu \mathrm{g} . / \mathrm{ml}$. each) to nutrient agar permitted the growth of $H$. influenzae, and that both factors were required, the addition of the two growth factors to a Casamino acids medium gave no growth even when supplemented with tryptophan and the ash from nutrient broth. By using the 'well' technique (see below), it was found that the addition of Tryptone (trypsin digested casein; Oxo brand) Stokes's yeast extract (Stokes, 1955), yeast extract dialysis diffusate (Cohen \& Wheeler, 1946) or autoclaved yeast extract dialysis diffusate to the Casamino acids + DPN + haematin + agar basal medium all permitted good growth. It was further found that the addition of glucose $(0 \cdot 1 \%, \mathrm{w} / \mathrm{v})$ to the Casamino acids + DPN + haematin + yeast extract diffusate medium resulted in a fiveto six-fold increase in yield. The addition of glucose to routine ' chocolate' agar medium, however, did not improve the yield. Treatment of the yeast extract dialysis diffusate with nitrous acid did not diminish its growth-promoting properties. Systematic investigations were therefore made to discover the growth-producing factors.

\section{METHODS}

Basal medium (g.): Casamino acids (Difco Technical), 1.2; NaCl, 0.3; Na glutamate, 0.15 ; cysteine $\mathrm{HCl}, 0.01 ; \mathrm{KH}_{2} \mathrm{PO}_{4}, 0.05 ; \mathrm{MgCl}_{2} .6 \mathrm{H}_{2} \mathrm{O}, 0.04 ; \mathrm{CaCl}_{2} .2 \mathrm{H}_{2} \mathrm{O}$, $0.001 ; \mathrm{FeSO}_{4} .7 \mathrm{H}_{2} \mathrm{O}, 0.00125$; $\mathrm{CuSO}_{4} .5 \mathrm{H}_{2} \mathrm{O}, 0.000125$; water to $100 \mathrm{ml}$. To this 
mixture was added $5 \%$ (w/v) granular charcoal (for gas-adsorption; British Drug Houses Ltd.), previously well washed with hot water to remove 'fines' and an appreciable amount of oily material. The medium was well stirred, filtered, adjusted to $\mathrm{pH} 7 \cdot 6$ with $\mathrm{NaOH}$ and $100 \mathrm{ml}$. volumes placed in $100 \mathrm{ml}$. (nominal) screw-cap bottles containing $\mathbf{1 \cdot 7 5}$ g. powdered agar (Difco); the mixture was sterilized and the agar dissolved by autoclaving at $121^{\circ}$ for $15 \mathrm{~min}$. with the caps screwed tight.

$D P N$ solution (1000 $\mu \mathrm{g} . / \mathrm{ml}$.). To $100 \mathrm{ml}$. sterile water were added and dissolved $100 \mathrm{mg}$. DPN, the solution sterilized by filtration through a $0.7 \mu$ Gradocol membrane and stored in the refrigerator.

Haematin solution. To $80 \mathrm{ml}$. distilled water were added $200 \mathrm{mg}$. $\mathrm{Na}_{2} \mathrm{CO}_{3}$ and $120 \mathrm{mg}$. haematin and the two completely dissolved. The solution was Seitz-filtered (6 cm. mat, grade S.B.) and the mat washed through with $20 \mathrm{ml}$. distilled water. This gave a solution of about $1 \mathrm{mg}$. haematin/ml. (nominal since the Seitz filter-mat adsorbed appreciable amounts of haematin). This solution was stored in the refrigerator.

Growth-factor solutions. These were prepared in sterile distilled water at $1 \mathrm{mg} . / \mathrm{ml}$., except biotin, cobalamine, coenzyme $\mathbf{A}$ and cytochrome $\mathrm{C}$ which were used at $50 \mu \mathrm{g} . / \mathrm{ml}$. and which were initially sterile.

The test plate. To $100 \mathrm{ml}$. of the melted agar basal medium, at $85-90^{\circ}$, were added: (i) $1 \mathrm{ml}$. (equiv. $1 \mathrm{mg}$.) DPN solution; (ii) $1 \mathrm{ml}$. (equiv. $1 \mathrm{mg}$.) haematin solution; (iii) $0.2 \mathrm{ml}$. of $50 \%(\mathrm{w} / \mathrm{v})$ glucose solution. About $30 \mathrm{ml}$. lots of this molten mixture were poured into sterile Petri dishes. A quantity of the medium was retained and held at $55-60^{\circ}$. When the plates had set, five holes, equally spaced at the periphery of the agar, were cut out by using a stainless-steel tube, diameter $6 \mathrm{~mm}$.; when necessary the cylinders of agar were removed with a sterile platinum wire.

To $5 \mathrm{ml}$. of the retained basal molten agar medium + DPN + haematin + glucose, in a tube, was added $0.1 \mathrm{ml}$. of the growth factor solution under test (giving a final concentration $20 \mu \mathrm{g} . / \mathrm{ml}$.). The tube was placed in boiling water for $3 \mathrm{~min}$. and then, with a sterile Pasteur pipette, sufficient mixture was poured in to fill one hole and allowed to set. Five different mixtures were used for each plate. A suspension of Haemophilus influenzae, taken from a $18 \mathrm{hr}$. heated blood agar plate, was made up in $1 \%(\mathrm{w} / \mathrm{v})$ neutral Casamino acids to a concentration of about $2 \times 10^{9}$ organisms/ $\mathrm{ml}$. Streaks of implant were made with a platinum loop from the centre of the plate radially to cross over the well of each test substance. The implants were dried and the plate incubated for $18 \mathrm{hr}$. at $34^{\circ}$. When the substance under test was the limiting factor for growth, its growth-promoting effect produced a line of heavy confluent growth over the 'well', extending centrally and diminishing to virtually no growth at the centre ('medium control' part) of the plate. Five different strains of $\boldsymbol{H}$. influenzae, obtained from the Routine Bacteriology Department, St Mary's Hospital, were used at the beginning of the investigation and fifteen different strains were used to check the conclusions.

\section{RESULTS}

\section{Initial attempt to identify the factor in yeast extract dialysis diffusate}

In these experiments it was assumed that only one supplementary growth factor was being provided by the yeast extract dialysis diffusate (hereafter yeast extract diffusate). By using the 'well' technique the following forty-eight substances were 
separately tested in the DPN + haematin + glucose augmented basal medium: adenine sulphate, adenosine-5-monophosphate, adenylic acid, $\beta$-alanine, alloxan, $p$-aminobenzoic acid, ascorbic acid, adenosine triphosphate, biotin, cobalamine (vitamin $\mathrm{B}_{12}$ ), choline, coenzyme $\mathrm{A}$, cocarboxylase, cysteine hydantoin, cytochrome C, cytosine, folic acid, fructose-1:6-diphosphate, fructose-6-phosphate, gluconic acid, glucose-1-phosphate, glucose-6-phosphate, glutamine, glutathione, glycerol, $\beta$-glycerophosphate, glyoxylic acid, guanine, meso-inositol, hypoxanthine, nicotinamide, nicotinic acid, oleic acid, pantothenic acid, phospho-enol-pyruvic acid, 3-phosphoglyceric acid, pimelic acid, pyridoxamine $\mathrm{HCl}$, pyridoxal phosphate, riboflavin, thiamine $\mathrm{HCl}$, thiamine monophosphate ester, lipoic acid, thymine, uracil, vitamin $\mathbf{E}$, vitamin $K$, xanthine. Not one of these compounds had any significant growth-promoting effect; nor did haemolysed washed horse red cells or boiled horse red cells. A mixture of basal medium and yeast extract diffusate $(20 \%, \mathrm{v} / \mathrm{v})$ was always used on each plate as a positive control and always showed the growth-promoting effect.

\section{Identification of four supplementary growth factors required by Haemophilus influenzae}

Since not one of the forty-eight substances listed above had any growth-promoting effect for Haemophilus influenzae on the DPN + haematin + glucose augmented basal medium, whereas the addition of yeast extract diffusate did, it was decided to make an 'artificial yeast extract' and test this, as it now appeared probable that more than one supplementary growth factor was required and that all were present in the yeast-extract diffusate. The artificial yeast extract mixture was prepared to contain the following twenty-eight substances all at $1 \mathrm{mg}$. $/ \mathrm{ml}$. except for biotin and cobalamine which were at $50 \mu \mathrm{g}$. $/ \mathrm{ml}$.: adenine sulphate, adenosine-5-monophosphate, $\beta$-alanine, alloxan, $p$-aminobenzoic acid, adenosine triphosphate, biotin, cobalamine, co-carboxylase, cytochrome $\mathrm{C}$, cytosine, folic acid, glutamine, guanine, hypoxanthine, meso-inositol, L-leucine, lipoic acid, nicotinamide, pantothenic acid, pimelic acid, pyridoxamine $\mathrm{HCl}$, riboflavin, thiamine $\mathrm{HCl}$, thiamine monophosphate ester, thymine, uracil, xanthine.

This mixture, diluted $1 / 50$, promoted the growth of Haemophilus influenzae on the deficient medium more strongly than $20 \%(\mathrm{v} / \mathrm{v})$ of yeast extract diffusate. This confirmed the idea that two or more supplementary growth factors were required. The identification of the individual growth factors in the mixture was carricd out as follows. To a molten sample of the basal medium were added two substances, e.g. $a+b$, and the mixture tested; to this mixture was then added substance $c$ and the new mixture tested; to this mixture was added substance $d$ and so on until the final mixture contained all the twenty-eight substances. From the results obtained a new 'complete' mixture was obtained containing fewer substances than the original twenty-eight as well as one identified growth factor. The latter was mixed with substance $a$ to become a new first mixture, and the whole process repeated. For the next series the first mixture became the two identified growth factors only and the second mixture, these two substance $+a$ and so on.

In point of fact the analysis was not as straightforward as expected, for two reasons: (i) not all strains tested had the same requirements; (ii) there were alternative, but chemically related, substances which gave the same growth-promoting 
effect. This was shown by another type of experiment, the 'one-missing' technique, namely, testing mixtures of the twenty-eight substances in which one of the twenty-eight substances was omitted in each case. Two substances were found to be absolute requirements for all strains, namely, pantothenic acid and uracil (uracil not replaceable by cytosine or thymine). The third growth factor was found to be thiamine, which was replaceable by co-carboxylase or thiamine monophosphoric ester. The fourth factor was a purine, not required by all strains. Of the four nucleotide purines tested, adenine had no growth promoting effect, but guanine, xanthine and hypoxanthine were interchangeable, with hypoxanthine the most effective. Uric acid had no growth promoting effect for purine-dependent strains planted on a purine-deficient medium. The addition of cysteine (or glutathione) to the Casamino acids basal medium was essential for growth. From these experiments a satisfactory medium was developed and may be prepared as follows.

Stock solution 1. 1\%(w/v) DPN. To $100 \mathrm{ml}$. distilled water is added and dissolved 1 g. $95 \%$ DPN (Light and Co., Colnbrook, Bucks., England, or C. F. Boehringer \& Söhne, Mannheim, W. Germany) and sterilized by filtration through a Gradacol membrane ( $0.7 \mu$, mean pore diameter) and stored in the refrigerator.

Stock solution 2. $0.5 \%$ Haematin in a solution of $1 \%(\mathrm{w} / \mathrm{v}) \mathrm{Na}_{2} \mathrm{CO}_{3}+5 \%(\mathrm{w} / \mathrm{v})$ $\mathrm{NaHCO}_{3}$. To $180 \mathrm{ml}$. distilled water is added $2 \mathrm{~g}$. $\mathrm{Na}_{2} \mathrm{CO}_{3}+1 \cdot 1 \mathrm{~g}$. haematin, and complete solution facilitated by gently warming; in this solution is then dissolved $10 \mathrm{~g}$. $\mathrm{NaHCO}_{3}$. The solution is sterilized by Seitz-filtration, and the mat washed through with $20 \mathrm{ml}$. distilled water. The excess $10 \%(\mathrm{w} / \mathrm{v})$ haematin is added to compensate for its marked adsorption by the filter mat. This solution is stored in the refrigerator and protected from light.

Stock solution 3. $50 \%(\mathrm{w} / \mathrm{v})$ Glucose solution. A $\mathbf{5 0} \%(\mathrm{w} / \mathrm{v})$ solution of glucose in distilled water, sterilized by autoclaving at $121^{\circ}$ for $15 \mathrm{~min}$.

Stock solution 4. Uracil, hypoxanthine and cysteine $\mathrm{HCl}$ solution. To $200 \mathrm{ml}$. $0 \cdot 1 \mathrm{~N}-\mathrm{HCl}$ is added $1 \mathrm{~g}$. uracil $+1 \mathrm{~g}$. hypoxanthine $+10 \mathrm{~g}$. cysteine $\mathrm{HCl}$, and solution facilitated by gently warming.

The complete medium. To 1 l. distilled water is added $25 \mathrm{~g}$. Oxoid no. 2 dehydrated nutrient broth (this provides an adequate supply of thiamine and pantothenic acid) and to this is added $2 \mathrm{ml}$. of stock solution 4 and $15 \mathrm{~g}$. Davis agar (Davis Gelatine Co. Ltd., Warwick). The mixture is autoclaved in $1 \mathrm{l}$. bottle for $15 \mathrm{~min}$. at $121^{\circ}$. After autoclaving and while the medium is still hot are added: $1 \mathrm{ml}$. stock solution 1, $2 \mathrm{ml}$. stock solution $2,2 \mathrm{ml}$. stock solution 3 . The medium is well mixed and dispensed into 30 to 35 Petri dishes $(9 \mathrm{~cm}$. diam.). This complete medium contains per ml.: $10 \mu \mathrm{g}$. each DPN, haematin, uracil, hypoxanthine; $100 \mu \mathrm{g}$. cysteine $\mathrm{HCl}$; $1 \mathrm{mg}$. glucose; about $0 \cdot 7 \mathrm{mg}$. $\mathrm{NaHCO}_{3}$.

The harvest from an overnight culture $\left(34^{\circ}\right)$ on this medium is about $10^{10}$ organisms/ml. medium, which is about five times the yield from a chocolate agar plate. The organisms are uniformly minute coccobacilli.

\section{Supplementary observations}

Enriched blood-agar plate. The above complete medium may be used as the nutrient agar base for a blood plate, but only horse blood should be used (see below). When this especially enriched blood plate is used in routine bacteriology the colonial appearance of most microbes is different from usual. Not only does Haemophilus 
influenzae grow freely but all pneumococci and streptococci grow exceptionally profusely, although with some alteration in their usual haemolytic characteristics. Thus : (i) $\beta$-haemolytic streptococci show greatly decreased haemolysis; (ii) 'viridans' streptococci show a narrower zone of green but a deeper green below the colony; (iii) pneumococci show almost no green zone, but cause the medium to appear almost black below the colony; the $18 \mathrm{hr}$. colonies are domed, not umbilicated, are very smooth and glistening, with a marked 'wet' appearance.

The chocolate agar plate and Haemophilus influenzae

It is common experience that whereas Haemophilus influenzae grows very poorly on a blood agar plate it grows luxuriantly when the same medium has been rapidly heated to $80-100^{\circ}$. More precisely, the growth of $H$. influenzae is poor on horse blood agar, very poor on human blood agar and does not occur on sheep blood agar; all become apparently equally good after heating. The fact that the organism grew luxuriantly on the heated blood medium showed that this contained all the necessary growth substances in the unheated state. The problem was therefore to account for the very greatly diminished growth on the unheated medium. The growth of $H$. influenzae on nutrient agar supplemented with $10 \mu \mathrm{g} . / \mathrm{ml}$. each of DPN and haematin was equal to that on a control chocolate agar plate. The omission of either growth factor from the nutrient agar prevented growth. That the failure of $H$. influenzae to grow on blood agar was not due solely to the two growth factors merely being inaccessible by being locked-up in the red cell was shown by culturing the organism on: $(a)$ sheep blood agar medium in which the red cells had been lysed by distilled water or by saponin; $(b)$ sheep blood agar to which had been added $10 \mu \mathrm{g} . / \mathrm{ml}$. each of pure haematin and DPN. In neither case did the $H$. influenzae grow. The possibility of growth inhibition by the serum moiety of the blood was excluded, since the same results were obtained when washed red cells were substituted for whole blood. On the other hand, it was found that the incorporation of heated washed sheep red cells in the nutrient agar base permitted luxuriant growth. These latter experiments suggested that it was not the sheep serum that prevented growth, and that the red cells were the source of both growth factors despite the absence of growth in the presence of intact or lysed red cells.

The yeast cell (a rich source of DPN) contains a DPN-pyrophosphatase, and in the extraction of DPN from yeast it is necessary to heat the cells rapidly to $80-100^{\circ}$ to destroy this enzyme and thereby protect the simultaneously liberated coenzyme from hydrolysis (Tauber, 1949). From this it seemed probable that sheep red cells might contain a pyrophosphatase or diphosphopyridine nucleosidase (DPNase). That this is so was shown by incubating washed sheep red cells with pure DPN; the supernatant fluid from this mixture failed completely to permit growth of $\boldsymbol{H}$. influenzae when added to a DPN-deficient medium.

In contrast to these findings with sheep blood agar the addition of haematin and DPN to a horse-blood agar plate permitted luxuriant growth of Haemophilus influenzae, and washed horse red cells did not inactivate DPN. H. influenzae grew well on a routine horse blood agar plate when the red cells had been haemolysed with saponin. From all this it is concluded that sheep red cells, but not horse red cells, contain a DPNase. By lysing washed sheep red cells with distilled water and 
separating, by centrifugation, the stroma from the released haemoglobin, it was found that the stroma destroyed the DPN but that the stroma-free haemoglobin solution did not.

\section{DISCUSSION}

Two points arising from the above observations may be discussed: $(a)$ the success experienced in the past on the growth of Haemophilus influenzae by workers using only peptone + DPN + haematin; $(b)$ the type of DPN-splitting enzyme present in the sheep red cell stroma. (a) The Tryptone (a tryptic digest of casein) used in the prcliminary work described above afforded moderate growth when added to the Casamino acids basal medium; from this it would seem that the enzyme preparation used to make the digest contained sufficient uracil, hypoxanthine, thiamine and pantothenic acid to permit moderate growth. Peptone, because of its meat origin, would contain more of all these growth factors.

(b) There are two types of DPN-splitting enzymes, a pyrophosphatase which hydrolyses the molecule to give nicotinamide mononucleotide and adenylic acid, and a nucleosidase (DPNase) which splits off nicotinamide. Gingrich \& Schlenk (1944), using a peptone medium, found that nicotinamide riboside showed a Vfactor activity for $H$. influenzae but was less efficient than DPN. Since the effect of the DPN-splitting enzyme in the sheep red cell stroma abolished the growthpromoting effect of a considerable excess of DPN it is thought probable that the enzyme in the stroma is of the nucleosidase type (DPNase) as was found by Hofmann $\&$ Rapoport (1955) to be the case in rabbit red cell stroma.

\section{REFERENCES}

Cohen, S. M. \& Wheeler, M. W. (1946). Pertussis vaccine prepared with Phase-I cultures grown in fluid medium. Amer. J. publ. Hlth, 36, 371.

Davis, D. J. (1917). Food accessory factors (vitamins) in bacterial culture with special reference to hemophilic bacilli, J. infect. Dis. 21, 392.

Davis, D. J. (1921 a). Accessory factors in bacterial growth: IV. 'Satellite' or symbiosis phenomenon of Pfeiffer's bacillus (B. influenzae). J. infect. Dis. 29, 178.

DAvis, D. J. $(1921 b)$. Accessory factors in bacterial growth: V. Value of satellite (or symbiosis) phenomenon for classification of hemophilic bacteria. J. infect. Dis. 29, 187.

Finnes, P. (1921). The nature of the effect of blood-pigment upon the growth of $B$. influenzae. Brit. J. exp. Path. $2,16$.

GiNGRICH, W. \& ScileENK, F. (1944). Co-dehydrogenase I and other pyridinium compounds as V-factor for $H$. influenzae and $H$. parainfluenzae. J. Bact. 47, 535.

Hofmann, E. C. G. \& RAPOPORT, S. (1955). DPN- und TPN-spezifische Nukleosidasen in Erythrozyten. Biochim. biophys. Acta, 18, 296.

Lwoff, A. \& LwoFf, M. (1937 a). Studies on co-dehydrogenases. I. Nature of growth factor 'V'. Proc. Roy. Soc. B, 122, 352.

Lwoff, A. \& Lwoff, M. (1937 b). Studies on co-dehydrogenases. II. Physiological function of growth factor 'V'. Proc. Roy. Soc. B, 122, 360.

Lwofr, A. \& Lworf, M. (1937c). Role physiologique de l'hemine pour Haemophilus influenzae Pfeiffer. Ann. Inst. Pasteur, 59, 129.

Lworf, A. \& Pirosky, I. (1937). Détermination des facteurs des croissance pour Haemophilus ducreyi. C.R. Soc. Biol., Paris, 124, 1169.

Stokes, E. J. (1955). Clinical Bacteriology, p. 271. London: Edward Arnold (Publishers) Ltd.

TAUBEr, H. (1949). The Chemistry and Technology of Enzymes, p. 213. London: Chapman and Hall. 